\title{
Knowledge and Attitudes about HIV/AIDS among Homoeopathic Practitioners and Educators in India
}

\author{
Adeline Nyamathi ${ }^{1}$, Vijay Pal Singh ${ }^{2}$, Ann Lowe ${ }^{1}$, Anil Khurana ${ }^{2}$, Divya Taneja ${ }^{2}$, \\ Sheba George ${ }^{3}$ and John L. Fahey ${ }^{4}$ \\ ${ }^{1}$ School of Nursing, University of California, Los Angeles, California, USA, ${ }^{2}$ Central Council for Research in \\ Homeopathy, Delhi, India, ${ }^{3}$ Research Centers in Minority Institutions, Charles R. Drew University of Medicine \\ and Science and ${ }^{4}$ UCLA David Geffen School of Medicine, Los Angeles, California
}

\begin{abstract}
This study is designed to assess AIDS knowledge among Homeopathy educators and physicians in India, which has not been evaluated previously. India now has the largest number of HIV infected persons worldwide, with an estimated cumulative 5.1 million infections. Homeopathy is the dominant system among the nationally-recognized alternative or complementary systems of medicine, which collectively provide health care to around 600 million people in India. Homeopathy, with its holistic and patient-centered approach, has a wide reach to people at risk of contracting human immunodeficiency virus (HIV). Participants were 68 homeopathy physicians (34 educators and 34 practitioners) who completed a CDC questionnaire measuring HIV/AIDS Knowledge regarding AIDS. This study reports the current level of knowledge of, and attitudes about, HIV/AIDS among homeopathy educators and practitioners. These findings will assist in the development of an education module to equip homeopathic health care personnel to impart accurate AIDS information and prevention counseling to their patients in an efficient manner.
\end{abstract}

Keywords: Education-HIV/AIDS-homeopathy-India

\section{Introduction}

The number of cases of human immunodeficiency virus (HIV)/acquired immunodeficiency syndrome (AIDS) has grown significantly since the first cases of a new form of immune deficiency were reported in the United States of America in 1981. Gradually, but steadily, the disease has assumed a pandemic status and is now reported in all parts of the world. Whereas African countries have been devastated for several years (1), India is now emerging as the second most affected country, with an estimated 5.13 million people infected with HIV at the end of 2004 (2).

For reprints and all correspondence: Adeline Nyamathi, ANP, PhD, FAAN, UCLA, School of Nursing, Room 2-250, Factor Building, Box 951720, Los Angeles, CA 90095-1702, USA. Tel: +(310) 825-8405; Fax: (310) 206-7433; E-mail: anyamath@sonnet.ucla.edu
While antiretroviral (ARV) medications for treating HIV disease have been developed, these drugs have markedly improved quality of life for those consistently on drugs; however, these drugs only delay the progression of the disease and do not cure the infection. Accounts of HIV drug resistance, ranging from $27 \%$ to $50 \%$, have also been reported (3). Further, these drugs can be toxic, are highly priced, and unaffordable by most people who need them in the developing world (4). In India, a small number of government hospitals in several parts of the country are designated to supply basic ARV drugs to people with AIDS free of cost; however, only a fraction of those who need ARVs can receive them as treatment centers are still being developed. Thus, the majority of the Indian population with HIV infection are without free medications. Despite extensive research, a curative therapy or a therapeutic or preventive vaccine remains to be developed. Thus, prevention continues to be the best option to contain the pandemic. 


\section{Homeopathic Physicians Can Play a Critical role in HIV/AIDS Prevention and Education}

The Indian Systems of Medicine (ISM), of which homeopathy is the second largest component, provide health care to over 600 million people in India and have the potential to reach many high-risk populations in India in an efficient and cost-effective manner. While a number of HIV/AIDS studies that incorporate complementary and alternative therapies as treatment have been reviewed in the literature (5), fewer studies have been conducted related to homeopathy and the issue of HIV/AIDS treatment (6-8). A review of such studies is provided by Ullman (9). However, no studies have been conducted to assess the potential role of the homeopathic practitioner in providing HIV education and prevention. Yet, the role of ISM and homeopathic practitioners and educators in providing HIV education and prevention has not been investigated. Moreover, no significant efforts have been made to utilize the services of homeopathic practitioners in the delivery of prevention messages to their patients, many of whom are at risk of acquiring HIV. As there are 182 homeopathic colleges and more than 200000 active homeopathic practitioners in India who could have a significant impact on disseminating knowledge about HIV (10), these homeopathic professionals could be very significant in reducing the numbers of HIV-infected people.

\section{Purpose of the Study}

The present study was designed to assess the current level of HIV/AIDS cognitive and transmission-related knowledge among homeopathic educators and practitioners; both of whom play critical roles in impacting HIV/AIDS in India. Homeopathic educators are the disseminators of knowledge to the future generations of homeopathic practitioners, and thus, are essential sources of knowledge. Homeopathic practitioners are the connection to the community, and often times, the populations at risk for HIV. Findings from this study will be used to develop a culturally-sensitive HIV/AIDS education and training program that could be integrated into the homeopathy curricula. The study also aims to equip homeopathic educators and practitioners as the future disseminators of HIV/AIDS knowledge and HIV transmission to their future students, clients and the public, in general.

\section{Methods}

\section{Design}

This study of homeopathic physicians was part of a larger study designed to examine the HIV/AIDS knowledge of these traditional health care providers. After receiving a full description of the study goals and procedures and the informed consent procedure, as approved by the University of California at Los Angeles, Human Subjects Protection Committee and the Central Council for Research in Homeopathy Ethics Committee, participants who had been previously engaged in a focus group session, completed a self-administered Centers for Disease Control and Prevention (CDC) AIDS Knowledge and Attitude questionnaire.

\section{Sample and Setting}

Data were collected from 68 participants, 34 educators and 34 practitioners, from Pune and New Delhi. Pune is located in the State of Maharashtra in western India, where HIV prevalence is relatively high. The participants were almost equally represented in terms of gender. Individuals were eligible to participate in the study if they had been homeopath educators or practitioners for at least 6 months, were over the age of 18 and were willing to participate in the initial focus group sessions conducted prior to the questionnaire administration.

\section{Procedure}

Data were collected between 2003 and 2005 by the US and Indian collaborators. Participants were recruited by means of flyers that were posted in the homeopath newsletter and in the academic settings in Delhi and Pune. These flyers directed interested persons to call or visit the research staff who were located at the Central Council for Research in Homeopathy $(\mathrm{CCRH})$ headquarters in Delhi.

After completing informed consent, participants attended a 75-min focus group session (total of eight), conducted in a large private room at the $\mathrm{CCRH}$ and academic setting headquarters. The focus group sessions were aimed at determining the: (i) current role and functions of homeopathy practitioners in the delivery of disease prevention messages, especially those related to HIV/AIDS; (ii) perspectives of both homeopathy educators and practitioners about HIV/AIDS training received and beliefs about the importance of, barriers to and facilitators of, delivering effective HIV prevention education in their clinical practice; (iii) applicability of community-based participatory approaches for future use and (iv) ease of implementing an AIDS prevention training program utilizing the 'Train the Trainer' process. Finally, participants completed a sociodemographic questionnaire and an AIDS knowledge and attitudes questionnaire. Due to the generally smaller sample size required for qualitative studies, the study was powered to detect only large differences between the educator and 
practitioner groups on dichotomous measures. However, there was good power for detecting moderate differences of half a standard deviation on continuous knowledge measures.

\section{Instruments}

AIDS knowledge and attitudes were assessed by a 21-item subset of the questionnaire developed by the Centers for Disease Control and Prevention and modified by Leake et al. (11). The potential range of the overall knowledge scale is $0-21$. In a sample of homeless adults, these items were found to factor well as a single scale and as two subscales related to cognitive knowledge (such as 'AIDS can damage the brain' and 'A person with AIDS can look and feel well') and transmission of the AIDS virus (such as 'A person can get AIDS virus infection from shaking hands, touching or kissing on the cheek of someone who has the AIDS virus?'). The internal consistency (chronbach's alpha) of the overall scale in the current sample was 0.81 and the knowledge of transmission subscale was 0.88 . Some of the cognitive items loaded on multiple factors. Since these items were diverse, we formed a knowledge index, with possible scores from 0 to 9 , by summing the number of cognitive items answered correctly.

\section{Sociodemographic Factors}

A structured instrument assessed self-report of age, education, marital status and history of employment.

\section{Data Analysis}

Descriptive analysis consisted of frequencies and percentiles or means and standard deviations, depending on the level of the data. Chi-square tests, two-sample $t$-tests and correlations were used to assess associations between selected sociodemographic factors, including practitioner versus educator differences in knowledge of HIV/AIDS.

\section{Results}

\section{Sociodemographic Characteristics}

Participants were between 22 and 58 years of age, with a mean age of 38 years; the majority $(96 \%)$ was Hindus and all were full time employees. Educators were somewhat older (40 years) compared with their practitioner counterparts (36 years). They were also more likely to be married $(91 \%)$ as compared with the homeopathic practitioners $(82 \%)$. Of the participants, $82 \%$ were homeopathic graduates, while $18 \%$ were postgraduates in homeopathy. Data are presented in Table 1.
Table 1. Sociodemographic characteristics of homeopathy physicians by group

\begin{tabular}{|c|c|c|c|c|c|c|}
\hline & \multicolumn{2}{|c|}{$\begin{array}{l}\text { Homeopathic } \\
\text { practitioners }\end{array}$} & \multicolumn{2}{|c|}{$\begin{array}{c}\text { Homeopathic } \\
\text { educators }\end{array}$} & \multicolumn{2}{|c|}{ Total } \\
\hline & Mean & SD & Mean & SD & Mean & SD \\
\hline \multirow[t]{2}{*}{ Age } & 36.4 & 9.4 & 40.2 & 7.7 & 38.3 & 8.8 \\
\hline & $N$ & $\%$ & $N$ & $\%$ & $N$ & $\%$ \\
\hline Hindu religion & 65 & 97 & 32 & 94 & 65 & 96 \\
\hline Marital status & 28 & 82 & 31 & 91 & 59 & 87 \\
\hline
\end{tabular}

\section{Responses to HIV/AIDS Knowledge Items}

The 21 items in the AIDS knowledge and attitudes questionnaire and summary statistics are presented in Table 2. When individual items were assessed, five questions appeared to be most problematic for both groups of physicians. Question 3, 'AIDS can damage the brain' was correctly answered by $21 \%$ of practitioners and $38 \%$ of educators. Question 5, 'A person can be infected with the AIDS virus and not have the disease' was correctly answered somewhat more often by both practitioners and educators (35\% vs $53 \%$ ). Homeopathic practitioners responded quite differently than their educator counterparts in another set of questions, namely question 10 'There is no cure for AIDS at present' $(56 \%$ vs $94 \%$ ), question 15 'One cannot get AIDS by sharing plates, forks or glasses with someone with AIDS virus' (76\% vs $88 \%$ ) and question 16 'One cannot get AIDS by using the public toilet' (79\% vs 91\%). Significant differences were found between practitioners and educators on two items 'There is a vaccine available to the public that can protect against the AIDS virus', $(56 \%$ vs $76 \%$, $P<0.04)$ and 'There is no cure for AIDS at present' $(56 \%$ vs $94 \%)$.

\section{Score Means on HIV/AIDS Knowledge}

Means for the overall instrument were calculated separately for homeopathic practitioners and educators. Homeopathic educators had a higher overall knowledge mean scale score $(X=17.4, \mathrm{SD} 2.8)$ compared with their practitioner counterparts $(X=15.9$, SD 3.8, $P<0.02)$. Cognitive knowledge also appeared to be somewhat higher among educators than among practitioners although the difference did not reach conventional statistical levels $(X=6.6$, SD 1.9 vs $X=5.6$, SD 1.7, respectively, $P<0.06$ ). No significant differences were noted between the groups with respect to knowledge of HIV transmission. For the most part, HIV transmission items were more likely to be answered correctly than cognitive knowledge items regardless of group. 
Table 2. AIDS knowledge by homeopathic professional role

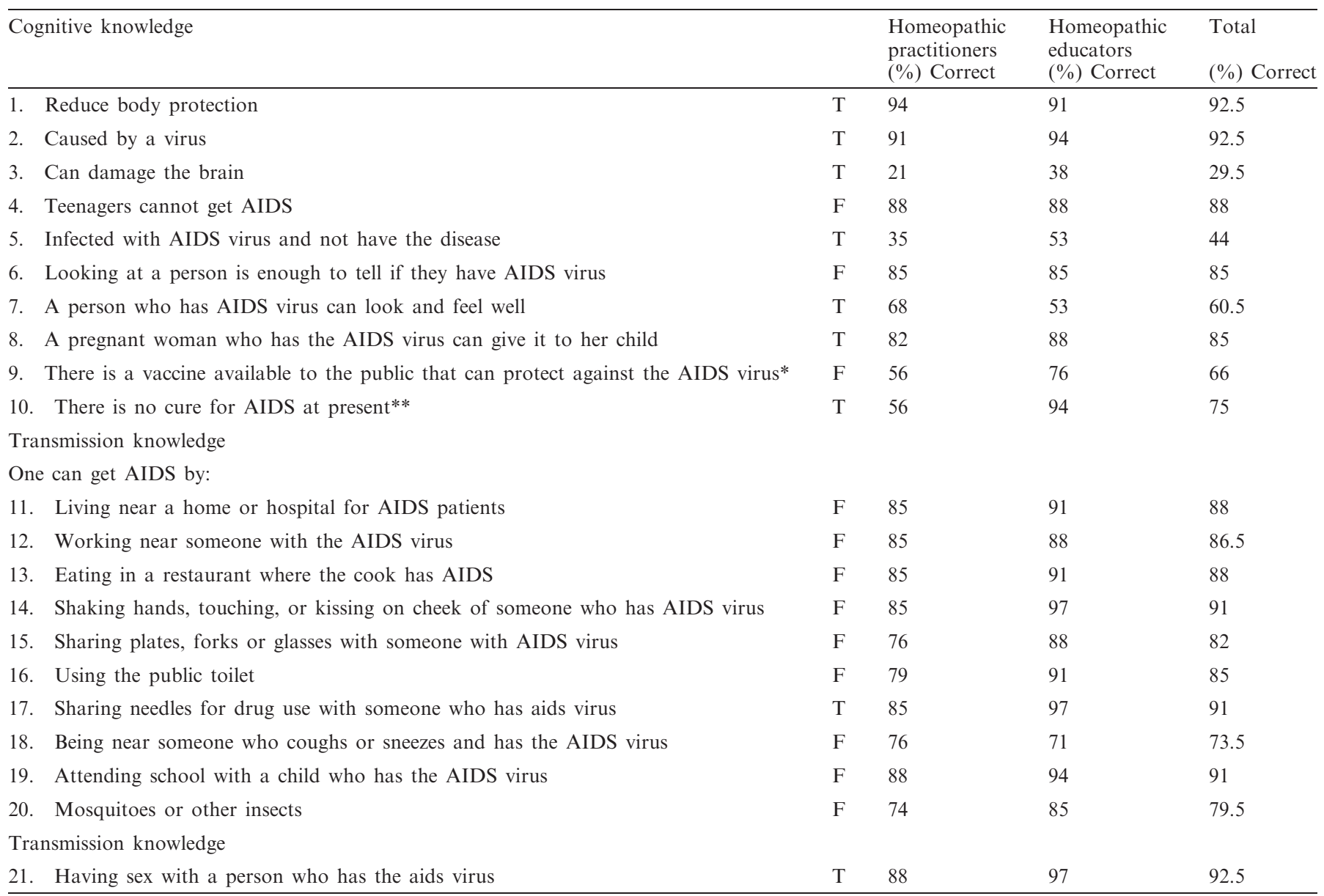

$* P<0.05 ; * * P<0.001$.

\section{Discussion}

This study was designed to assess AIDS knowledge and attitudes among homeopathy physicians and educators for the purpose of developing a more effective training program. Findings revealed that knowledge of AIDS transmission, the nature of HIV and the impact of the AIDS virus on the immune system was higher than other cognitive knowledge items. Few homeopathic physicians were aware that AIDS could damage the brain. In addition, $<75 \%$ of physicians were aware that a person with the AIDS virus can look or feel well, or that infection with the HIV virus and having the disease AIDS were separate stages of disease, these findings may partly be due to conceptual differences in the perceptions of disease in conventional medicine and homeopathy. The lack of cognitive knowledge was not surprising given that these participants verbalized in the previous focus groups a lack of organized CME for homeopathic practitioners; in fact, most of the participants had not received any training in HIV/AIDS and, therefore, demonstrated limited knowledge of HIV/AIDS. Clearly, education might assist with more information about the signs and symptoms of HIV/AIDS and clinical manifestations ranging from asymptomatic to symptomatic stages of HIV/AIDS for all health care providers.

A few items also revealed widely discrepant scores between homeopathic practitioners and educators. These items related to transmission of AIDS via the public toilet or mosquitoes, and whether there was an existing cure for AIDS. As HIV/AIDS is now becoming a topic of interest in the homeopathic colleges, and while still not comprehensively taught, the increased attention may explain the higher scores attained by the homeopathic educators.

The findings of this study indicate that more education on HIV/AIDS is needed for Indian homeopaths, through CME and other programs focusing on knowledge of AIDS and its transmission. This questionnaire, developed by the CDC, could be used as the basis for an education program, as it highlights particular areas of deficits.

There are multiple reasons why this study is important. First, India has one of the highest levels of HIV infection in the world. Second, AIDS prevention programs are relatively inexpensive; which is particularly important in India where ARV drugs are still not widely available 
Table 3. AIDS knowledge summary by groups

\begin{tabular}{|c|c|c|c|c|c|c|}
\hline & \multicolumn{2}{|c|}{$\begin{array}{l}\text { Homeopathic } \\
\text { practitioners }\end{array}$} & \multicolumn{2}{|c|}{$\begin{array}{l}\text { Homeopathic } \\
\text { educators }\end{array}$} & \multicolumn{2}{|c|}{ Combined totals } \\
\hline & Mean & SD & Mean & SD & Mean & SD \\
\hline \multicolumn{7}{|l|}{ Cognitive } \\
\hline Knowledge** & 5.56 & 1.7 & 6.59 & 1.9 & 6.1 & 1.8 \\
\hline \multicolumn{7}{|c|}{ Transmission of AIDS } \\
\hline Virus & 7.47 & 2.7 & 8.12 & 1.5 & 7.8 & 2.2 \\
\hline Combined factors* & 15.85 & 3.8 & 17.44 & 2.8 & 16.6 & 3.4 \\
\hline
\end{tabular}

$* P<0.06 ; * * P<0.02$.

free of charge. Additionally, homeopaths are one of the largest of the Indian complementary or alternative health care providers - providing care to about 600 million often hard-to-reach high-risk people. As complementary and alternative therapies are considered, in a recent study, to hold promise for the treatment of symptoms or diseases by many western physicians (12), the plea for ongoing evidence-based information is needed. Thus, as global assessment has not yet been performed on the Homeopathic System of Medicine regarding HIV/AIDS knowledge and attitudes, this step is critical before a more effective training program can de developed for homeopaths and other ISM practitioners; thus leading the way to further knowledge development and integration into clinical practice settings (13).

\section{Limitations}

This study was part of a larger one that obtained qualitative data from focus groups, and quantitative data from questionnaires addressed to homeopathic educators and practitioners. The results reported here reflect the quantitative aspects; there are several limitations. First, the sample size is relatively small, including only 34 educators and 34 practitioners. Second, these health care providers came from two large cities, Dehli and Pune, and may not reflect the knowledge and attitudes of those in more remote areas. Finally, as the participants were recruited by flyers and newsletters, they may represent only a subset of homeopathic physicians.

\section{Conclusion}

Prevention of HIV/AIDS is complex, requiring multiple strategies to reach more remote, high-risk people. Homeopaths provide promise of an alternate way to approach the problem. In the future, longitudinal studies should be conducted to track the knowledge and attitudes of this significant group of providers to determine the efficacy of changing educational curricula on both homeopathic physicians and their clients. In particular, there is a need to impart focused training on prevention counseling about HIV disease to those already in practice. Moreover, it is imperative to educate and train the educators and practitioners of the homeopathic system of medicine, keeping in mind the rising incidence of HIV infection. The training module for such purposes must address health issues as well as cultural and societal taboos, sexuality, gender, religion, etc. This training must be supplemented with continued education on HIV/AIDS and related issues and encompass both the homeopathic colleges and current practitioners.

\section{Acknowledgement}

This study is funded by the World AIDS Foundation, No. WAF 324(03-046).

\section{References}

1. UNAID. The AIDS Pandemic in the 21st Century. International Population Reports. 2004

2. NACO. HIV/AIDS Indian scenario: estimation of HIV infections among adult population. 2004.

3. Garrett L. HIV drugs losing power for many. San Francisco Chronicle. December 18, 2001. Nation \& World Section, A3.

4. Solomon S, Chakraborty A, Yepthomi RD. A review of the HIV epidemic in India. AID Educ Preven 2004;16 (3 Suppl A):155-69.

5. Wootton J, Sparber A. Surveys of complementary and alternative medicine: Part III. Use of alternative and complementary therapies for HIV/AIDS. J Altern Complement Med 2001;7:371-77.

6. Colebunders R, Dreezen C, Florence E, Pelgrom Y, Schrooten W Eurosupport Study Group. The use of complementary and alternative medicine by persons with HIV infection in Europe. Int J STD AIDS 2003;14(10):672-74.

7. Rastogi DP, Singh VP, Singh V, Dey SK, Rao K. Homeopathy in HIV infection: a trial report of double-blind placebo controlled study. Br J Homeopath 1999;88(2):49-57.

8. Singh N, Squier C, Sivek C, et al. Determinants of non-traditional therapy use in patients with HIV infection. Arch Intern Med 1996;156:197-201.

9. Ullman D. Controlled clinical trials evaluating the homeopathic treatment of people with human immunodeficiency virus or acquired immune deficiency syndrome. J Altern Complement Med 2003;9:133-41.

10. Annual Report. Ministry of Health and Family Welfare, Government of India. 2005.

11. Leake B, Nyamathi A, Gelberg L. Reliability, validity and composition of a subset of the CDC AIDS knowledge questionnaire in a sample of homeless and impoverished adults. Med Care 1997; 35:747-55.

12. Wahner-Roedler D, Vincent A, Elkin P, Loehrer L, Cha S, Bauer B. Physicians' attitudes toward complementary and alternative medicine and their knowledge of specific therapies: a survey at an academic medical center. Evid Based Complement Alternat Med 2006;3(4):495-501.

13. Marotta F. Complementary and alternative medicine in clinical practice. Complementary and allopathic medicine: the hospital as a place of possible integration. Evid Based Complement Alternat Med 2006;3(4):549-50.

Received October 10, 2006; accepted January 16, 2007 


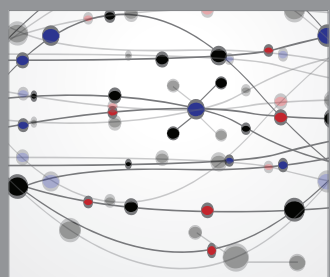

The Scientific World Journal
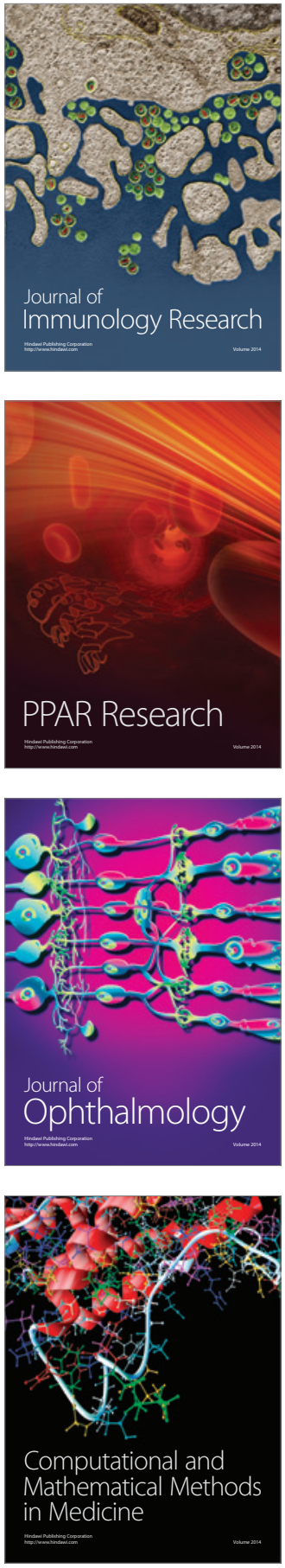

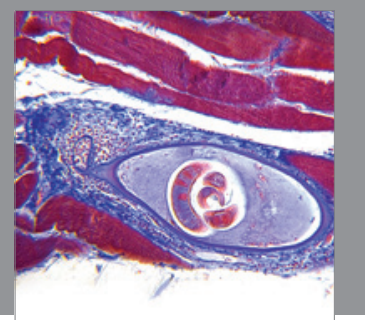

Gastroenterology

Research and Practice
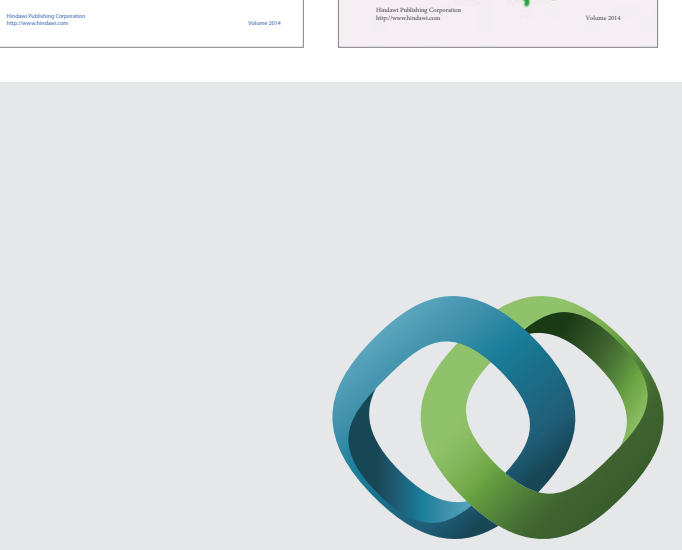

\section{Hindawi}

Submit your manuscripts at

http://www.hindawi.com
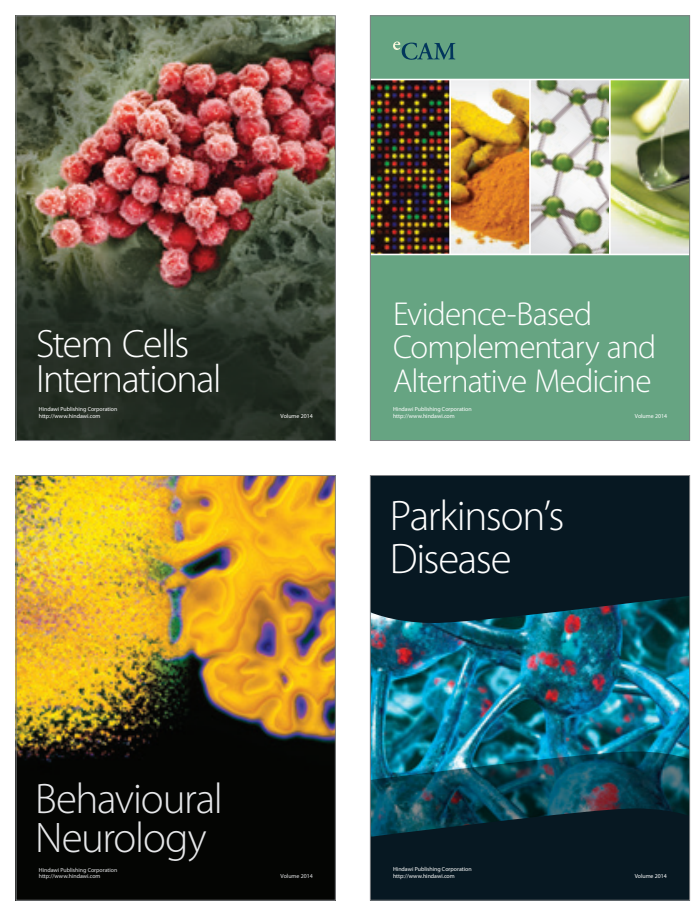

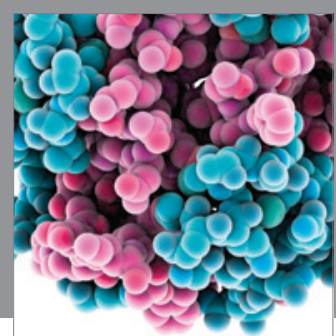

Journal of
Diabetes Research

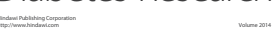

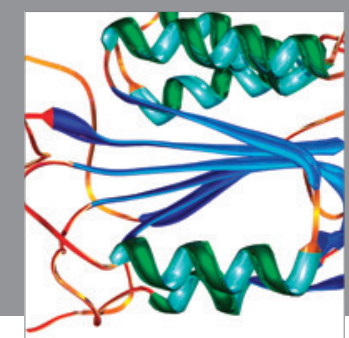

Disease Markers
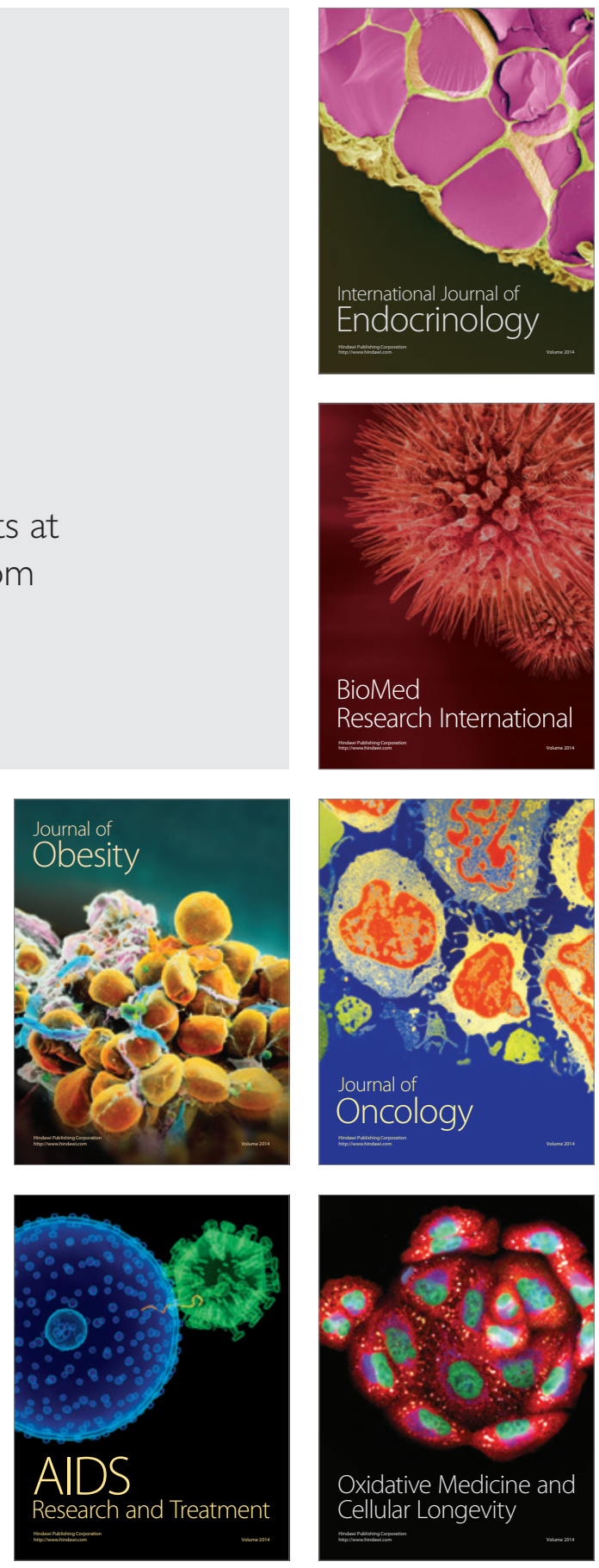